\title{
Monitoring the Curriculum through the Student Perspective
}

\author{
Erin D. Malone $\square$ Margaret V. Root Kustritz $\square$ Aaron Rendahl $\square$ Laura K. Molgaard
}

\begin{abstract}
Student input was deliberately included as part of the curriculum implementation and assessment plan at the University of Minnesota College of Veterinary Medicine. The new curriculum included design features to encourage deeper learning such as a spiral curriculum with cross-course integration, increased open time, and more active learning. Student well-being was seen as a simultaneous need. To gather overall perceptions of workload and well-being, student volunteers from each cohort were surveyed weekly starting in 2013. Survey questions asked about outof-class work time, level of integration, extracurricular activities, student well-being habits, paid employment, and other factors. Survey questions were combined with course data to get a full picture of week quality, total course work time, extracurricular activities, and the effects of integration. Many of our hypotheses about curricular and extracurricular impacts on week quality were disproven. Week quality was most positively affected by student factors of sleep and exercise, whereas the curricular factors of out-of-class work time, total course work time, and examination hours had the strongest negative effects. A surprising finding was that open time, in-class hours, and paid employment hours had a minimal effect on week quality. Students identified excessively heavy semesters and uneven semester workloads that resulted in early revisions to the new curriculum. Student feedback provided a view of the curriculum that was not otherwise available and resulted in early and significant impacts on the new curriculum, and they provided insight into whether planned changes had occurred and how effective various factors were in reaching the curricular goals.
\end{abstract}

Key words: curriculum implementation, curriculum revision, outcomes assessment, student perspective, student well-being, student workload, student survey

\section{INTRODUCTION}

The University of Minnesota College of Veterinary Medicine (UMN CVM) started implementing a curricular revision in 2013. ${ }^{1}$ The overarching goals of the revision included stimulating student clinical reasoning, problem-solving, and decision-making skills and promoting knowledge retention while maintaining student well-being. The objective of this article is to describe our processes and assessments, how we used them to identify both intended and unintended outcomes, and their usefulness in structuring further curricular revisions. The four main components of the survey and our hypotheses are outlined next.

\section{Part I: Active Learning}

Active learning opportunities were encouraged as part of the curricular revision to facilitate reflection and application of material rather than straight memorization. ${ }^{2}$ To support deep learning that would, we hoped, lead to better retention, open time in the schedule was deemed necessary. ${ }^{3}$ Content was removed to create open time, and course creators were encouraged to limit lecturing and add active learning opportunities.

We hypothesized that at least $10 \%$ open time would be required for student well-being. Moreover, we hypothesized that, if achieved, both increased active learning and open time of more than $10 \%$ would be positively correlated with weekly satisfaction scores.

\section{Part 2: Student Workload}

Caps on semester credit hours and individual course sizes were instituted as part of the curricular revision to support student learning and well-being by planning for a 4-year program with a heavy but sustainable workload and by avoiding disparities in course credit hours that would influence student study habits toward certain courses. ${ }^{4,5}$ The original goal was to create 40 - to 60 -hour work weeks ( 28 credits maximum) that included all course-related work, including time spent in class and time required outside of the classroom for study. ${ }^{1}$ The majority of courses were designed to be between two and five credits to encourage even distribution of study efforts. We hypothesized that a 60-hour work week (combined in-class and out-of-class time) was reasonable and would not negatively affect student well-being. Moreover, we hypothesized that the increased open time would permit students to distribute their studying for more effective retention. ${ }^{6}$

\section{Part 3: Curricular Flow and Integration}

To further strengthen retention, a spiraling curriculum was implemented to revisit important topics at increasing depth 
or complexity over time. ${ }^{7}$ We hypothesized that students would be able to identify curricular gaps and redundancies and would be more satisfied with higher levels of integration. In addition, we paid careful attention to test scheduling as part of the new curriculum. Although students frequently asked for more frequent and smaller examinations, we hypothesized there would be a level at which examination hours per week would outweigh the value of smaller tests as a result of increased anxiety and stress. ${ }^{4}$

\section{Part 4: Student Well-Being Factors}

We hypothesized that sleep would have a positive effect on student well-being and weekly satisfaction scores and that increased hours of paid employment and club activities would have a negative effect because of increased workload. ${ }^{8}$ We hypothesized week satisfaction scores would give a more complete picture of the curriculum and would allow us to identify problem areas early and to identify if changes were effective.

To address these four components, we strived to answer the following questions:

1a. Did active learning time increase in the new curriculum?

$1 b$. Were week quality scores correlated with active learning time, open time, or both?

2a. Did the student-reported workload match the estimated workload (course credit hours and total credit hours per semester)?

$2 b$. Did the weekly out-of-class time data show evidence of distributed studying or of intense studying before tests?

2c. Were week quality scores correlated with total workload, in-class hours, or out-of-class work time?

2d. Was the workload achievable while also maintaining student well-being?

3a. Did students identify and appreciate integration efforts?

3b. Could students identify excessive redundancy and curricular gaps?

3c. Were week quality scores correlated with the perceived level of integration?

$3 \mathrm{~d}$. Were week quality scores correlated with the number of examinations per week?

4a. Were week quality scores correlated with sleep, extracurricular activities, paid employment, or exercise?

4b. Could week quality scores be used as an early warning system for curricular issues?

Because many of these questions could not be readily measured without student input, the UMN CVM partnered with students to help determine whether the goals were met and to identify problematic areas as well as bright spots. Students were surveyed weekly about their level of satisfaction with the week (week quality), individual well-being factors, out-of-class work time, and the effectiveness of the curriculum (particularly integration, contradictions between courses, and content gaps). We included well-being factors to determine how much of the student week quality score was related to noncurricular factors and to identify the level of selected healthy practices. ${ }^{9}$ In-class hours and types of activities (examinations, discussions, lectures, etc.) were added to the data to create a more complete picture of the week and for correlation with the week quality and integration scores.

\section{METHODS}

\section{Survey Components}

\section{Part I: Active Learning}

For each semester, usage of the active learning classroom, the amount of "chair time" (classes held in the lecture hall), and unscheduled time were monitored to answer Questions 1a and 1b.

"Chair time" reports were developed using GTimeReport (https://gtimereport.com/) and UMN CVM class calendars. Each class session was identified in Google Calendar by course name and number as well as by room assigned. Each hour of a 40-hour week was classified as lecture, discussion, laboratory, examination, or open time. If the scheduled time was more than 40 hours per week, the overage counted as a negative number. Quizzes were classified as 30- or 60-minute exams. If needed, a class hour was further subdivided into types in 30-minute chunks. For laboratories, often given to a subsection of the class and then repeated, we used student time rather than the entire session time. Electives were not subdivided by type of activity, and students were assumed to take all possible electives to create the maximum work week for calculations. Because of block tuition (which means that electives do not increase tuition costs), UMN CVM students generally take advantage of as many electives as possible. Maximizing work week hours also decreased the risk of overestimating effects of workload by biasing data in the opposite direction (e.g., 60-hour weeks reported as too stressful might actually have been 58 -hour weeks but were still too stressful). Week-long breaks and final exam weeks were not included in the calculations; short weeks including university holidays were included. We calculated the ratio of lecture to active learning time to verify changes between the curricula.

The UMN CVM remodeled an existing laboratory to become the CVM Active Learning Classroom (ALC). This room opened in September 2013 (one year into the new curriculum). Faculty in all years of the curriculum use this space for case discussions, small group work, microscopic laboratories, and the like. Lecturing is restricted by policy, and students provide feedback if faculty use the space for lecture. We monitored ALC usage by semester as a related metric for discussions and laboratories and to ensure sufficient space for curricular needs.

Students in the first six of eight semesters were asked to rate their weeks in terms of quality, with anchors of sustainability and enjoyment (see Appendix 1, available online at https:/ / doi.org/10.3138/jvme.0418-038r1, for the current survey). Comments were requested when a given student rated week quality as low. These ratings were converted into scores ranging from 0 (very bad) to 4 (great).

\section{Part 2: Student Workload}

The voluntary workload survey asked students to record how much time they spent on coursework and related activities outside of class, helping to monitor overall workload and to evaluate our credit calculations. Workload patterns were evaluated to identify whether students massed or distributed their studying. 
When courses were proposed for the new curriculum, many included projects and outside-of-class work. The Curriculum Committee asked faculty for estimates of worktime required; the resulting figures were generally considered inaccurately low. ${ }^{10}$ The first surveys asked students to report project time directly but it was obvious that students were not sorting out project from general work time, clouding the results. Subsequent surveys asked for work time in general. Data were collected to answer Questions 2a-2d.

To determine total workload, instructional times as listed in Google Calendar and syllabi were combined with reported out-of-class work time beginning in 2015. Before 2015, data were less reliable because of lower numbers of reporting students and differently phrased questions; that information is not included here. Course credits were initially assigned on the basis of an estimate of 3 hours of work for each lecture hour, combined with additional laboratory hours. Because we did not consider this number a reliable reflection of course work (total hours would exceed the hours in a week), we compared hours of in-class time and reported out-of-class work with the 28-hour maximum credit load distributed across the courses based on relative number of credit hours.

\section{Part 3: Curricular Flow and Integration}

Spiral curricula require close attention to both horizontal and vertical integration to ensure appropriate redundancy on the correct topics. ${ }^{11}$ A curriculum coordinator position was created to improve cross-course interactions and to help with test placement across the semester (maximizing time between tests while still connecting the tests to the relevant content). An end-of-semester evaluation was developed to assess the curriculum as a whole, particularly for appropriate redundancy, integration, and missing or extraneous information. In 2016, this evaluation was changed to specific questions in the workload survey to obtain more timely and accurate information. Data were collected to answer Questions 3a-3d.

Students were asked to rate the integration for the week's activities. These ratings were converted into scores ranging from 1 (poor) to 4 (excellent). Comments were requested for integration issues, content overlaps or gaps, extraneous content, and suggestions for the following year.

\section{Part 4: Student Well-Being Factors}

Various noncurricular factors have shown to be stressors and protectors of student well-being. $4,8,9$ Because our data showed relatively high levels of dissatisfaction with the curriculum and with apparent differences between cohorts, questions about potential well-being factors were added to the survey over time. Data were collected to answer Questions 4a and $4 \mathrm{~b}$.

Surveyed well-being factors included at least 6 hours of sleep, participation in weekly and weekend club activities, participation in non-veterinary activities, and amount and reason for exercise. Exercise was added only in September 2017, and related data are not included here.

"Bad" weeks, as identified in the survey question on week quality, were compared qualitatively with curricular activities (examinations, projects) to determine the cause of student stress levels. Student comments were collated and distributed to the Curriculum Committee.

\section{Survey Management}

Students from each cohort in years 1-3 were recruited at the start of each semester via email and in-person requests. All volunteers were accepted.

There was no penalty if a student missed a weekly survey. All survey responses were kept anonymous, and the curriculum coordinator reviewing the surveys did not know who was participating in the process. A staff member maintained a list of participants that was used to issue invitations to an end-of-year luncheon and prize drawing. That meeting, besides serving as a reward for participation and an incentive for continued involvement, was also used to revise the survey questions for the following year, discuss recruiting plans, and obtain student input on other topics such as learning management system formats. The project (Study 00002692) was deemed exempt from review by the institutional review board.

\section{Survey Administration}

Surveys were developed in Qualtrics XM (Qualtrics, Provo, UT) and updated as needed on the basis of student input. Surveys were developed with mobile phone use in mind, using the mobile-friendly alerts in the system for guidance. Volunteers completed the surveys weekly, with a reminder link sent on each Friday to submit information about the preceding 7 days. We chose the survey frequency to enable more accurate data collection while not overloading students with another task. Including date verification in the survey made it easier to ensure that students were reporting on the correct week.

Survey responses were downloaded weekly by a staff member, added to a secure folder, and subsequently reviewed by the curriculum coordinator. Initially, the surveys were reviewed at the end of the semester. However, it quickly became apparent that more frequent monitoring was both indicated and useful, and surveys were checked weekly when possible.

Summaries of the survey responses were distributed at the end of each semester to the Curriculum Committee, college and academic affairs leadership during the curricular implementation, and then as requested or as deemed useful by the curriculum coordinator after implementation.

\section{Data Analysis}

We analyzed only objective data (classroom hours, ALC usage) for the old curriculum and revised curriculum through 2015 because of initially low survey response rates and minimal questions on the original surveys. Unless otherwise reported, data include only the first five semesters because the sixth semester at UMN CVM is highly tracked, with students selecting courses on the basis of species interest.

We compared integration scores for corresponding semesters (e.g., first semester of 2016 and first semester of 2017) using paired $t$-tests across weeks. No attempt was made to integrate the sixth-semester courses because of student tracking by species; data from this semester were used as a baseline for integration efforts and compared with 
data from other semesters with an analysis of variance and Dunnett's comparison with control.

We compared week quality score averages with out-of-class workload, total workload, open time, examinations, active learning hours, paid employment, and well-being factors by using Spearman correlation analysis to identify potential relationships. For factors related to curricular design (inclass time, out-of-class workload, exams per week, etc.), we calculated cut-offs corresponding to the 75th percentile or higher for average scores of 2 (able to persist but not having fun) by performing quantile regressions with quadratic fit and reporting the value at which the fit went below 2, along with $90 \%$ bootstrap confidence intervals. Studentcontrolled well-being factors such as exercise, sleep, and paid employment were similarly analyzed. We include graphs because we could find no relevant data to scientifically select a cut-off; we chose a cut-off for average week quality scores of 2 on the premise that there will always be bad weeks but that having more than one-quarter of the weeks be bad would not be sustainable.

When applicable, we present descriptive data as means and standard deviations. We considered comparisons with $p<.05$ statistically significant.

\section{Curricular Re-Revision: Old Curriculum $\rightarrow$ New Curriculum $\rightarrow$ Revised Curriculum}

The new curriculum was further revised in 2016 because of issues identified through these surveys. Revision involved moving several courses and select content across semesters. Hence, we compared the last session of the old curriculum for each year of the program (2012-2013 for year 1, 2013-2014 for year 2, and 2014-2015 for year 3) and the stable version of the revised new curriculum (2016-2017 for year 1, 2017-2018 for years 2 and 3).

In 2013, the ALC opened. That room seated all students at once and was created to fulfill curricular goals. All but the students in the first year of the new curriculum were able to access that classroom as part of the curricular revision.

\section{RESULTS}

\section{Participants}

Survey data presented involve 15-27 participants per cohort, volunteering from classes of 102-104 students (12\%-22\%, mode of $15 \%$ ). Females were overrepresented in the survey participants in four of the five cohorts.

Student input on survey design, ensuring the survey was mobile friendly, and peer recruitment improved response rates. Students spoke to classmates about ease of use, helpfulness for identifying study habits, how the data had been used, and lack of faculty buy-in with low response rates. Response numbers doubled after involving the peer recruitment component.

\section{Part I: Active Learning}

\section{Question Ia: Did Active Learning Time Increase in the New Curriculum?}

The ratio of lecture to active learning time decreased from 2:1 in the old curriculum to $1.33: 1$ in the revised new curriculum when examinations were included as active learning rather than lecture. In other words, in the revised new curriculum, each hour of lecture was matched by approximately 0.75 hour of active learning time. If examinations were excluded from the calculations, the ratio decreased from 2.62:1 (old curriculum) to 1.72:1 (new curriculum).

Compared with the old curriculum, the revised new curriculum increased total discussion hours 147.5\% (from 110 to 271 hours), laboratory hours $1 \%$ (from 495 to 500 hours), and examination hours $23.8 \%$ (from 183 to 227 hours) over the first five semesters. ALC use similarly increased over time (Figure 1). Lecture hours decreased 16.4\% (from 1,583 hours to 1,323 hours), and elective hours decreased $16.8 \%$ (from 250 to 208 hours). In the old curriculum, lecture hours averaged more than 20 hours per week in three of the first five semesters: the third $(M=20.5$ hours, $S D=5.9)$, fourth $(M=21.7, S D=7.8)$, and fifth $(M=24.1, S D=6.1)$ semesters. After the 2016 revision, only the fifth semester remained above that mark at a mean of 20.6 hours per week $(S D=6.2)$. In both old and revised new curricula, the percentage of time spent in lectures increased each semester through the fifth semester (Figure 2).

The revised new curriculum resulted in an overall $12.6 \%$ decrease in total open time (540 hours to 472 hours over the first five semesters) compared with the old curriculum, with the most noticeable decreases in the first two semesters (Figure 2). The amount of open time was well above $10 \%$ for all three curricula (old, new, and revised new) with the exception of the fifth semester $(8 \%)$ in the initial new curriculum (September 2015).

\section{Question Ib: Were Week Quality Scores Correlated with Active Learning Time, Open Time, or Both?}

Open time between 8:00 a.m. and 5:00 p.m. had no obvious correlation with week quality ( $r=.09$; Figure $3 \mathrm{~A})$, and active learning hours had a slight negative impact $(r=-0.15)$, but with a nonlinear pattern.

\section{Part 2: Workload Survey}

\section{Question 2a: Did the Student-Reported Workload Match the Estimated Workload (Course Credit Hours and Total Credit Hours per Semester)?}

Students routinely spent many hours on course work outside of class $(M=19.9$ hours / week in the revised curriculum, $S D=7.6)$. When we compared total course effort (in-class and out-of-class hours) with course credit hours in 2016, we found relative discrepancies ranging from -1.2 to 3.3 credit hours per course, with an average official course credit hour underestimating the workload by a mean of 0.5 credits $(S D=0.1)$. On paper, the revised curriculum had no courses with a credit load of more than 5 credits and 15 courses with a credit load of less than 2 credits. However, when evaluated on workload, 7 courses had credit loads of more than 5 credits, and 20 had workload that would equate to credit loads of less than 2. Also, despite a stable curriculum with no course moves or approved changes in course credit allocations, for 2017 compared with 2016, semesters 1 and 2 increased by at least 1 credit of work and fifth-semester courses decreased by at least 2 credits of work. 


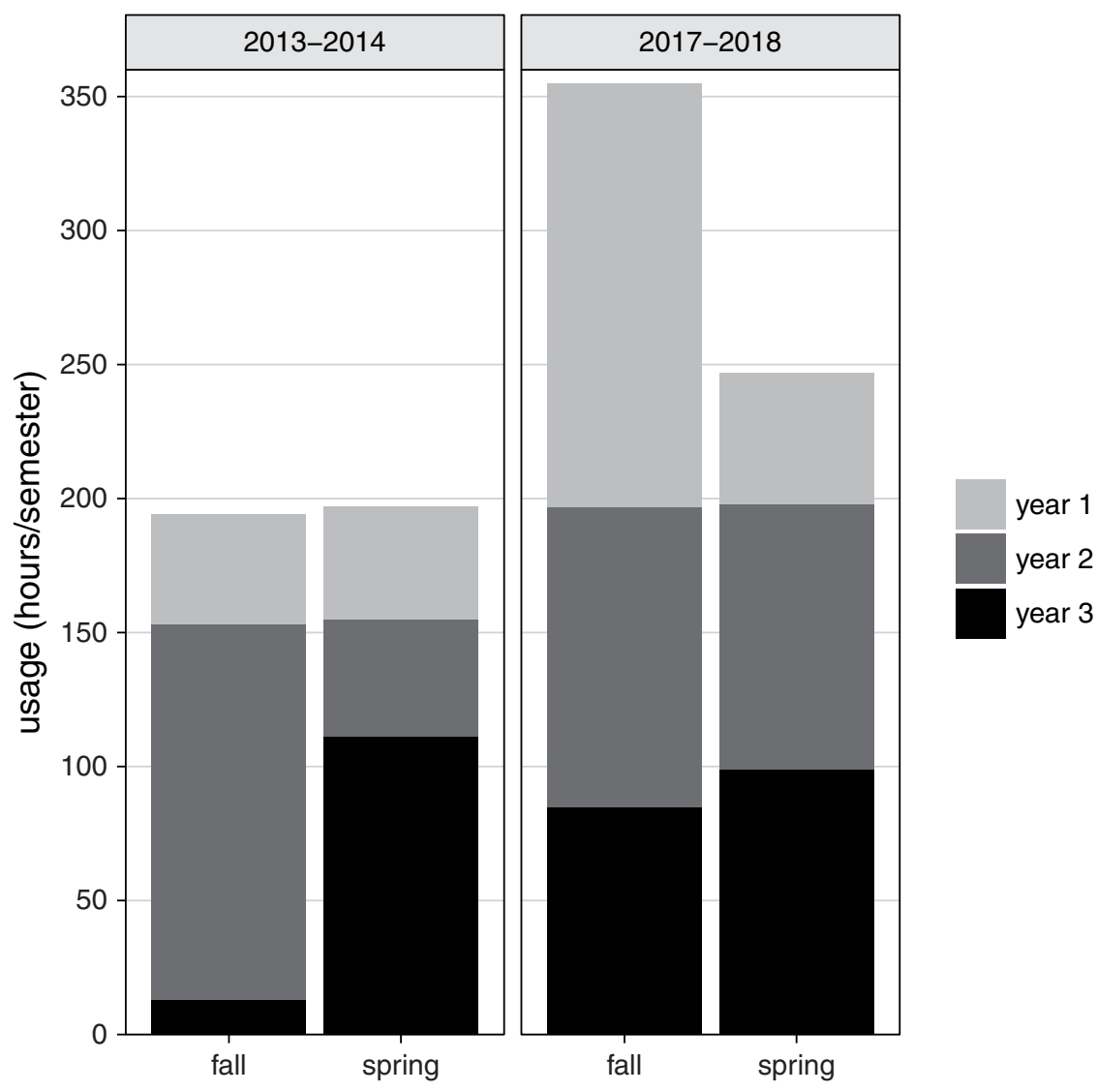

Figure I: ALC use over time in total hours per semester

The ALC opened in fall 2013, I year into the new curriculum. Usage is now relatively stable. The room is used for all imaging, microscopic, clinical pathology and physiology laboratories as well as for discussion sections on infectious disease, large animal surgery, pathology, and case-based presentations in most classes.

$A L C=$ active learning classroom

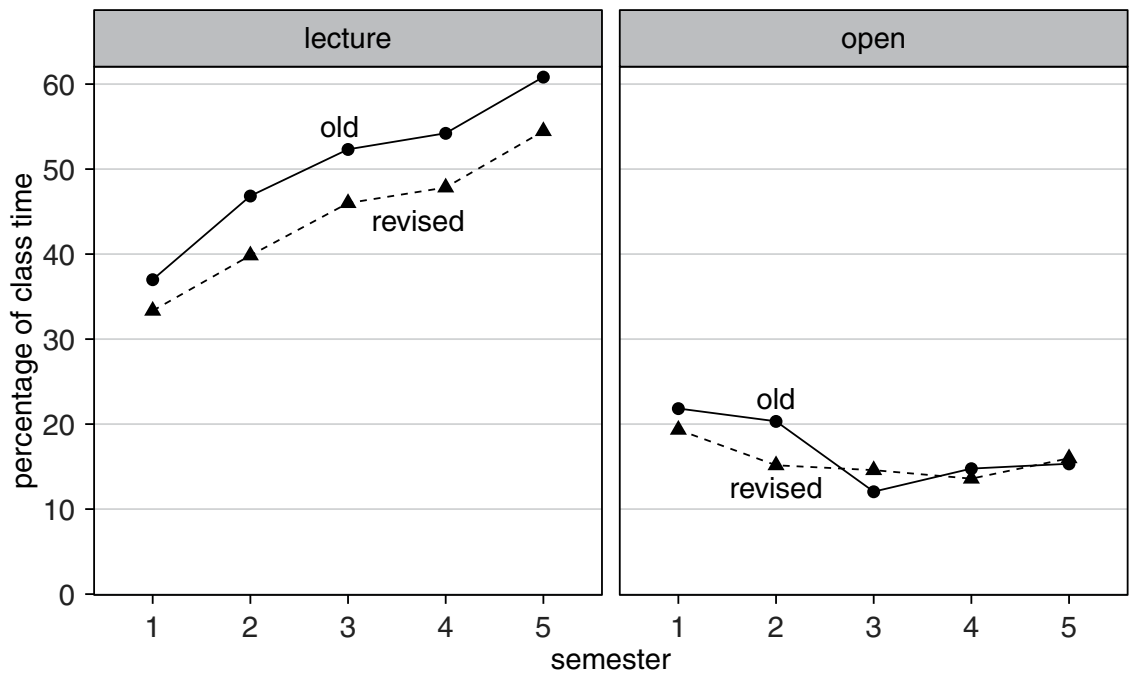

Figure 2: Average percentage of week spent in lecture or left open for each semester

The amount of time spent in lecture increases steadily by semester, with fifth semester students still spending more than $50 \%$ of the week in lecture in the new curricula. Basic science courses were more likely to add active learning sessions, clinical correlations and other group activities. Clinical courses made minimal changes in types of activities. The amount of open time decreased with the curricular revision, in part because of increased examination hours. 


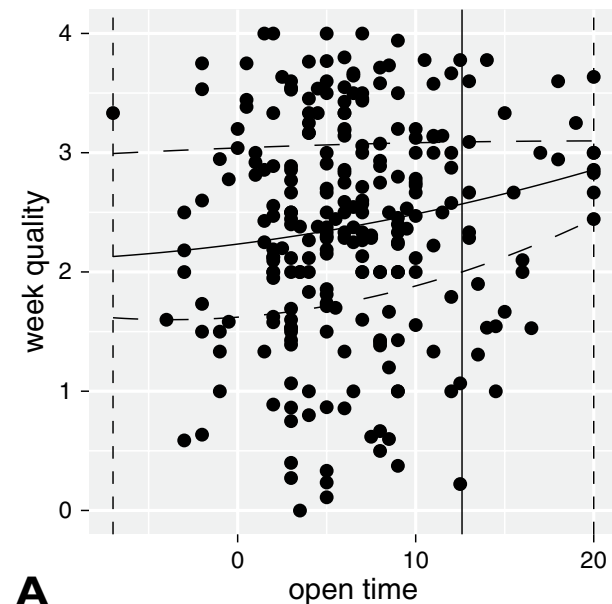

A

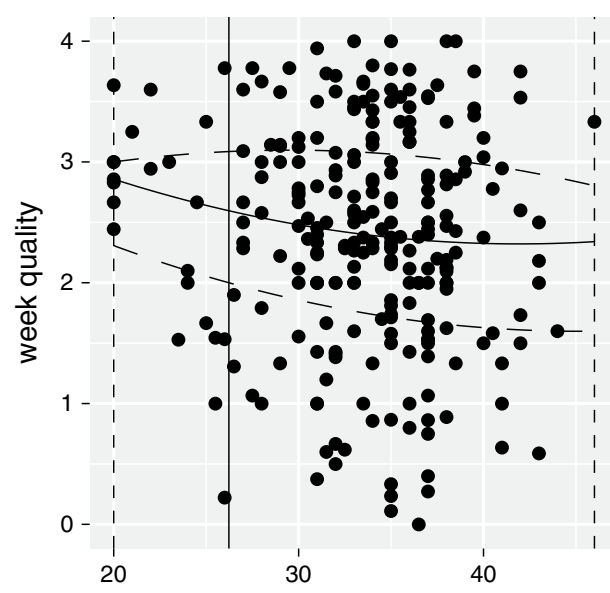

C

in class time

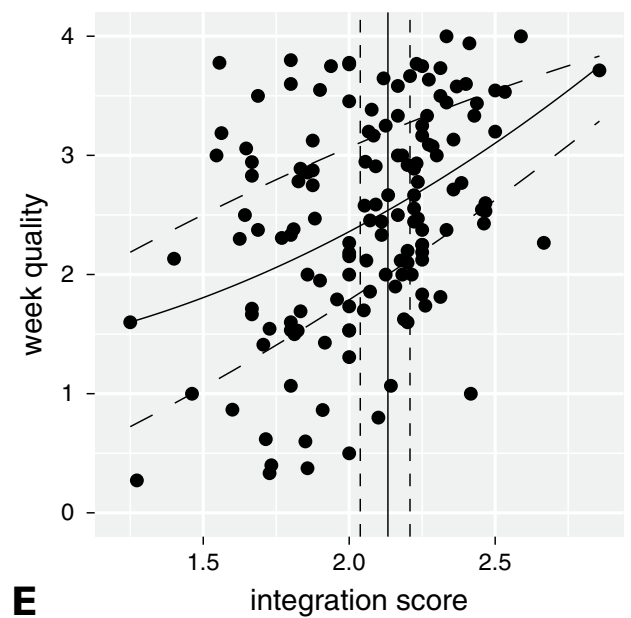

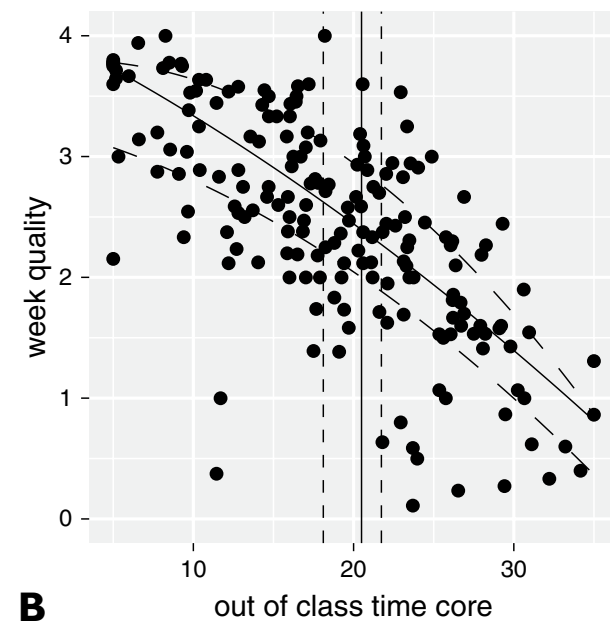
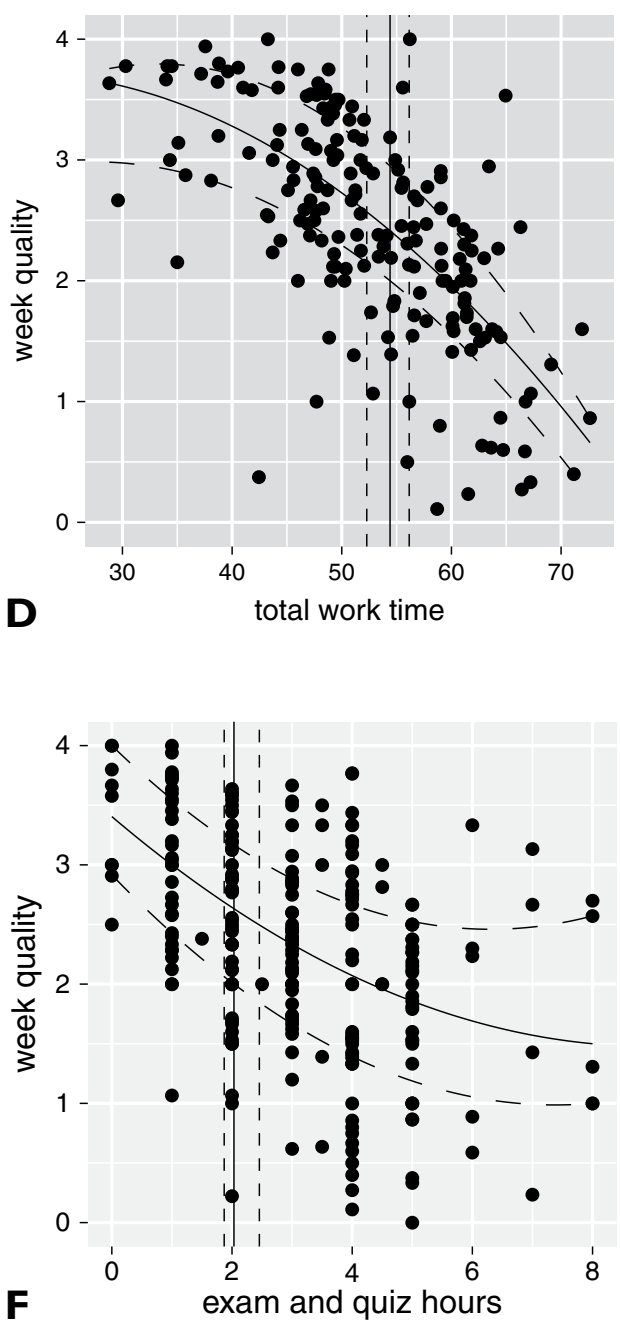

Figure 3: Regression curves for curricular planning: week quality with open time (A), core out of class time (B), in-class time (C), total work time $(D)$, exam and quiz hours $(E)$, and integration score $(F)$

Week quality scores are shown on the $y$-axis with hours or integration scores $(0=$ horrible; $4=$ excellent $)$ on the $x$-axis. Week quality scores were most strongly associated with out-of-class work time (3B), total work time (3D), number of examination or quiz hours per week (3F), and integration scores (3E). Minimal correlation was evident with open time between 8:00 a.m. and 5:00 p.m. (3A) or with in-class hours (3C). Vertical lines depict the hours or integration score at which $75 \%$ of the week quality scores were 2 or higher $(90 \%$ confidence). If that cut-off is desired, total work time should be maintained below $54-56$ hours per week, with out-of-class work time below 20-22 hours per week and examination and quiz hours below 2-2.5 hours per week. 


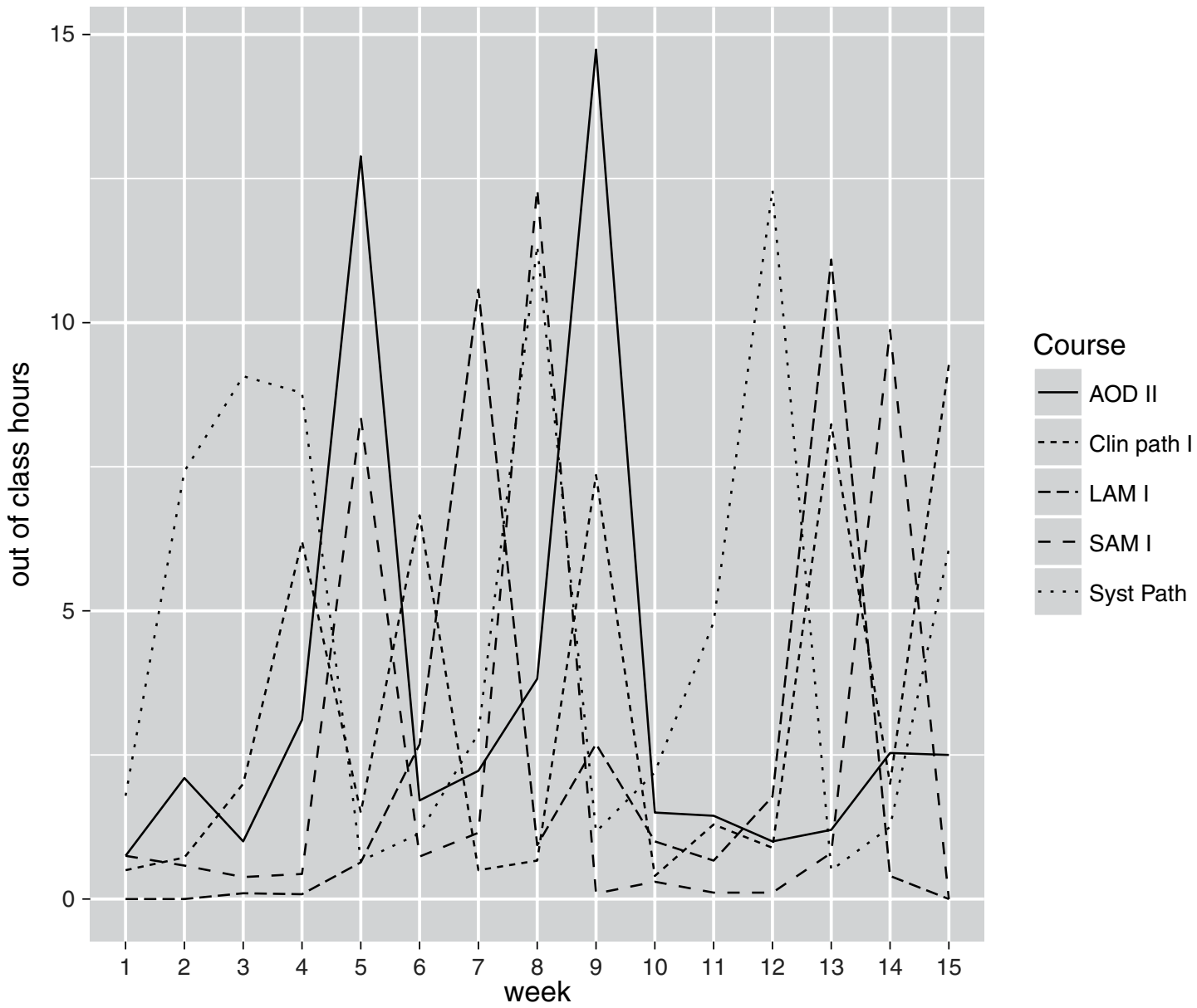

Figure 4: Example of out-of-class work time by course

Out of class work by week and by course or type of activity for selected courses in the third semester (2017). The peaks closely match large projects and major examinations. There is no evidence that students space their study sessions for a topic.

AOD = agents of disease $;$ Clin path I = Clinical Pathology I; LAM I = Large Animal Medicine I; SAM I = Small Animal Medicine I; Syst Path = systemic pathology

\section{Question 2b: Did the Weekly Out-of-Class Time Data Show Evidence of Distributed Studying or of Intense Studying Before Tests?}

Mapping the workload survey with activities generally showed peaks in course-related work based on upcoming examinations or major projects. There was no evidence that students distributed their studying (Figure 4).

\section{Question 2c: Were Week Quality Scores Correlated with Total Workload, In-Class Hours, or Out-of-Class Work Time?}

Week quality scores were negatively correlated with out-of-class work time $(r=-.70$; Figure 3B), total work time $(r=-.66$; Figure 3D), and week in the semester $(r=-.24)$. Data curves suggest that out-of-class time of 20.5 (range $=18.1-21.7$ ) hours and total hours of 54.4 (range $=52.3-56.2)$ should maintain $75 \%$ of average week quality scores of 2 or more (average week, can persist at this level but not much free time) in the UMN CVM program. Total in-class hours showed no obvious correlation with week quality $(r=-.9$; Figure 3C) when evaluated independently.

\section{Question 2d: Was the Workload Achievable While Also Maintaining Student Well-Being?}

At the level of the proposed 60-hour work week (in-class and out-of-class combined), most week quality scores averaged 2.5 or lower and $50 \%$ of the weeks averaged less than 2 .

\section{Part 3: Curricular Flow and Integration Survey}

\section{Question 3a: Did Students Identify and Appreciate Integration Efforts?}

The mean weekly integration score for the 2016 and 2017 sixth semester (not integrated purposefully) was $1.7(S D=0.3)$, or between "fair" and "good." This was significantly lower $(p<.01)$ than the other semesters for the same time period (ranging from 2.0 to 2.2 or "good"; $S E=0.2-0.3)$ with the exception of the first semester $(M=1.8, S D=0.3)$. Semester integration scores varied 

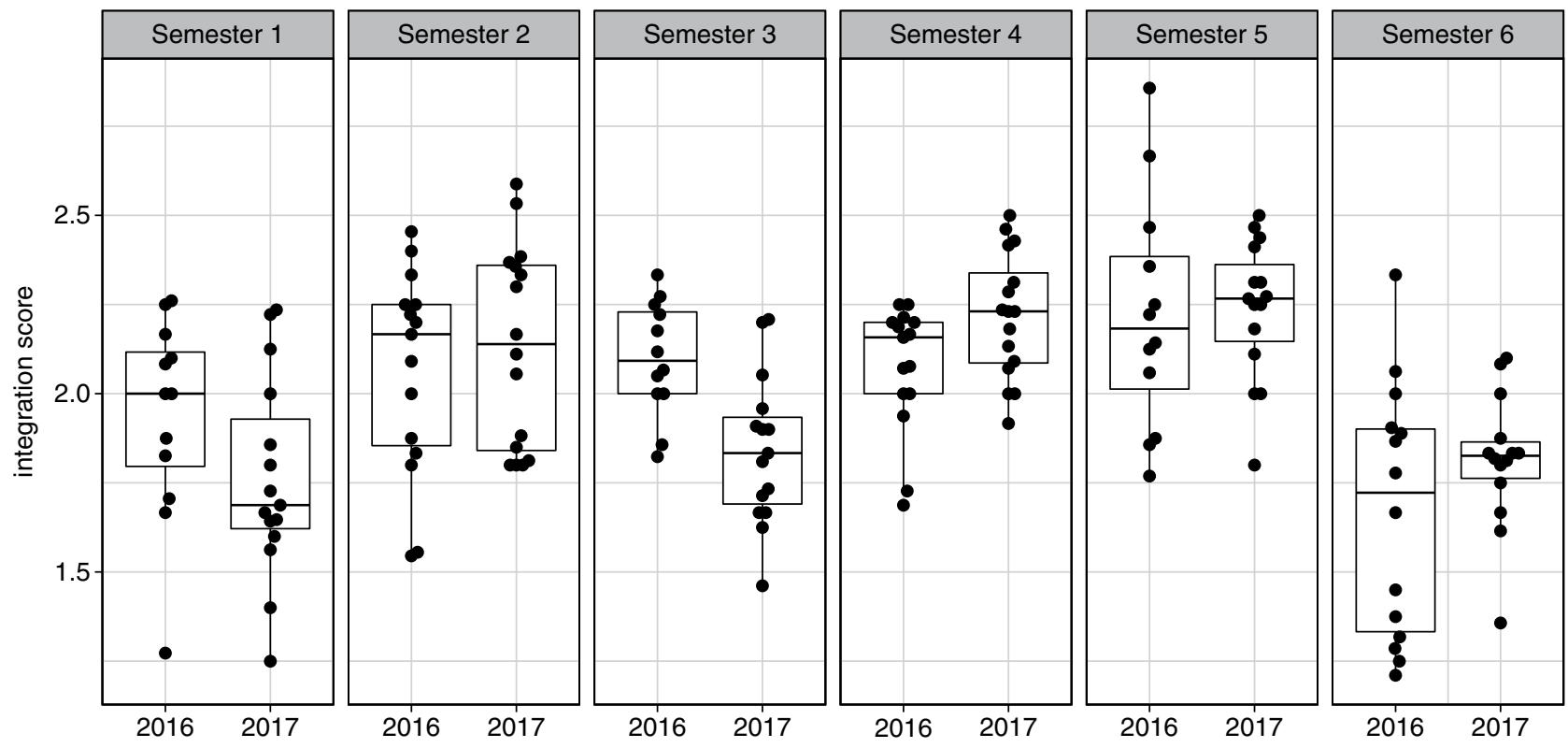

Figure 5: Average integration scores ( $1=$ poor, $4=$ excellent $)$ by semester and year

Despite efforts toward integration, semester integration scores decreased from 2016 to 2017 for the first and third semesters even as they increased for the fourth semester. Sixth-semester (not purposefully integrated) scores were significantly lower than in the second to fifth semesters $(M=1.7, S D=0.3$, vs. $M=2.1 S D=0.3$, for combined data; $p<.001)$.

over time and did not consistently match extra efforts toward integration (Figure 5).

\section{Question 3b: Could Students Identify Excessive Redundancy and Curricular Gaps?}

Students rarely complained about redundancy in content material, and most appreciated attempts to align content across courses. However, they found contradictions across courses highly frustrating and difficult when studying for examinations. Students varied in their preference for how distributed the material was over time but were uniform in disliking more than 2 hours of lecture in a single subject per day.

Students were also not able to identify areas of extraneous content. They frequently voiced concerns about "you will get this later" comments.

\section{Question 3c: Were Week Quality Scores Correlated} with the Perceived Level of Integration?

Week quality scores were positively correlated with integration score ( $r=.38$; Figure $3 \mathrm{~F})$.

\section{Question 3d: Were Week Quality Scores Correlated with the Number of Examinations per Week?}

Week quality scores were negatively correlated with examination hours per week $(r=-.46)$ and week in the semester $(r=-.24)$. At 2.0 (range $=1.9-2.5)$ exam or quiz hours per week, $25 \%$ of average week quality scores were 2 or lower. At 4 exam or quiz hours per week, $25 \%$ of the scores were 1.5 or lower (Figure 3E).

Other student recommendations for scheduling are listed in Appendix 2.

\section{Part 4: Student Well-Being Factors}

\section{Question 4a: Were Week Quality Scores Correlated with Sleep, Extracurricular Activities, Paid Employment, or Exercise?}

Week quality scores were positively correlated with getting at least 6 hours of sleep per night $(r=.77)$, participating in non-veterinary-related fun activities $(r=.50)$, and exercise $(r=0.48)$. Paid employment hours showed no obvious correlation with week quality $(r=.09)$.

\section{Question 4b: Could Week Quality Scores Be Used as an} Early Warning System for Curricular Issues?

Quality ratings of each week gave a strong and consistent picture of the semester. Students' comments provided a very clear picture of their mental status and were often stressful to read. Even though not solicited for higher quality weeks, students often provided comments about their week that gave additional insights:

It was not a bad week, but it felt exhausting being in class every day until 5:00 p.m. Getting out early today was great!

I liked having an exam on Tuesday and one on Friday. This is the best schedule when two exams are in 1 week.

I had some health issues outside of school that negatively impacted my ability to do work and succeed.

This was a great way to get back in the groove of school. The guest speaker on Thursday and Friday was great; he kept the class engaged, but it didn't require a lot of out of class time so we could ease into the semester. 
Overall a good week, just busy. Most of the "problems" this week were not really school related, more my own time organization and procrastination.

Once students "burned out" with a particularly bad week, they rarely had a good week again until after a holiday, despite easing up of course workload. Many students identified illness as a factor in adding to their stress levels. Life issues (family member illness or death, relationship issues, child care concerns) played a frequent role in adding to their anxiety. This was particularly noteworthy after the curriculum was first implemented. Very concerning comments were seen for the fourth and fifth semesters:

Weeks like this are why our profession has the highest suicide rate. This may sound like hyperbole, but I'm not kidding. This kind of workload-followed by another week that will be just as bad-promotes an unhealthy work ethic and utterly destroys any sense of work-life balance we're supposed to be having.

Don't let this happen next year. PLEASE. No one deserves this.

Too much this week. It's Monday afternoon and I can tell the whole class did too much studying this weekend because it's taking us over 30 seconds to comprehend things we are being asked

It was only a great week because I took a day off for myself because I was going crazy!

The deluge of information in school is simply too overwhelming.

This semester is too much. Morale is low.

I am beyond tired . . . increasingly apathetic and almost entirely beaten free of "good attitude." Quote from my wife: "I feel like I just have a subletter living in the basement for the last 2 months" Vet school needs to move out of the 1970s and start thinking about ACTUALLY becoming balanced and thinking about how pretty much all education research says well rested, less stressed people do a whole lot better than exhausted, emotionally fragile, stressed-thefrick-out people who feel like they are trapped in an endless cycle of cramming and testing.

Semester credit load and open time were reviewed both as planned and in response to the student comments received in the surveys. The fourth semester had higher credit loads than anticipated, and the fifth semester had minimal open time, seeming to correlate with the comments about poor week quality (Table 1). On the basis of this information, the Curriculum Committee approved the movement of several courses to balance credit load across all semesters.

Average week quality scores did not change significantly through the revisions: for the old curriculum, $M=2.3$, $S D=0.9$; for the initial new curriculum, $M=2.3, S D=0.9$; and for the revised new curriculum, $M=2.4, S D=0.9$

\section{DISCUSSION}

By identifying and monitoring select components of student workload and of the curriculum, we were able to determine if and when our curricular revision goals were met. Weekly input from students gave a nuanced picture of the curriculum's effect on their well-being and attitude toward
Table I: Open time by semester for each of the curricular revisions

\begin{tabular}{llll}
\hline & \multicolumn{3}{c}{ \% open time } \\
\cline { 2 - 4 } $\begin{array}{l}\text { Semester } 8) \\
\text { (old }\end{array}$ & $\begin{array}{l}\text { New } \\
\text { curriculum }\end{array}$ & $\begin{array}{l}\text { Revised } \\
\text { curriculum }\end{array}$ & curriculum \\
\hline 1 & 21.8 & 23.5 & 19.2 \\
2 & $20.3^{*}$ & 18.1 & 15.2 \\
3 & 12.1 & 17.8 & 14.6 \\
4 & $14.8^{*}$ & $15.9^{*}$ & $13.6^{*}$ \\
5 & 15.3 & 8.1 & 15.9 \\
\hline
\end{tabular}

Note: After the initial curricular revision, credits were unevenly distributed across semesters with the fourth semester at more than 30 credits, well over the planned 28 credit maximum. Similarly, the planned open time for the fifth semester was below the target of $10 \%$ or more. Student well-being comments were particularly negative for those semesters, leading the Curriculum Committee to adjust courses across all 3 years.

* Semesters with more than 28 credits

learning. The combination also identified unintended effects of the curricular change, variations between cohorts, and permitted us to see changes related to curricular revisions.

\section{Part I: Active Learning}

\section{Question I a: Did Active Learning Time Increase in the New Curriculum?}

Active learning time did increase in the new curriculum; unfortunately, open time concomitantly decreased because of an increase in examination hours. A curricular revision goal had been to free up time for exploration of topics of interest to students as well as to encourage active learning, and so this goal was only partially met.

With decreased lecture content, we would have expected examination hours to decrease rather than increase. In many instances, it appears lecture content did not decrease but was compressed into a shorter time frame. Instructors reported adding tests in response to student requests as well as to promote retention and ensure that students were reviewing the material, all of which seemed reasonable to the Curriculum Committee at the time of the requests. ${ }^{12}$

\section{Question Ib: Were Week Quality Scores Correlated with Active Learning Time, Open Time, or Both?}

Surprisingly, week quality scores were not correlated with open time and were slightly negatively correlated with active learning opportunities (discussions, laboratories). Many active learning sessions added new material rather than reinforcing or delving deeper into previously learned material and may have added to the workload rather than reinforcing knowledge or improving retention. Skills laboratories were not optimally designed and have since been revised to follow better motor skills learning principles. ${ }^{13}$ Alternatively, the time involved may have overridden any positive benefits of the sessions, at least in the minds of the students. Improved retention exam scores showed that the overall curriculum was effective in some manner; ${ }^{14}$ it is 
possible that student may just not have identified benefits at the time of the survey. ${ }^{2}$

Although open time in the schedule is probably useful for health appointments and business visits, the open time available in the new curriculum seemed to be overwhelmed by the workload. With students working an average of almost 20 hours out-of-class time per week, it should not be surprising that a few hours of open time did not create as much value as had been hoped. ${ }^{15}$ This would be even less likely as open hours decreased and examination hours increased. The semester with only $8 \%$ open time did have poor week quality scores and multiple comments about overwork; comments did improve after courses were reshuffled. A threshold effect may exist whereby a minimum amount of open time is needed for various out-of-class errands and health visits.

Although the outcomes were not as intended, the data are still considered valuable. The chair time report activities are now plotted out before the start of the semester to identify weeks with higher levels of in-class work time. Changes are made to balance exams and workload as much as possible. These graphs are shown to students in hopes that they can better plan for the heavy weeks and have the mental energy to persist, knowing it will not be that bad for the entire semester. The latest UMN CVM strategic plan increased the open time recommendation to $20 \%$; this is not being actively pursued. Rather, the college is focusing on identifying core content and decreasing the overall cognitive load.

\section{Part 2:Workload Survey}

\section{Question 2a: Did the Student-Reported Workload Match the Estimated Workload (Course Credit Hours and Total Credit Hours per Semester)?}

It was not surprising that our course credit hour metric did not match course workloads when calculated retrospectively. ${ }^{10}$ The UMN CVM metrics are based on undergraduate course credit paradigms and do not fit the professional program curriculum well. We did not initially include examination hours in course credit calculations. As those increased over time, the assigned credit levels became even more inaccurate. The student workload data also confirmed that we underestimate the time related for most projects. Discrepancies between actual and assigned course credit hours were used to argue for reduction in content, changes in credit levels, or both. In other cases, better defined expectations were implemented for activities that were using more student effort than faculty intended. At least one class moved from homework to solely in-class group work because veterinary students are often challenged by perfectionist tendencies and may find it hard to settle for "good enough" without strict time constraints., 46

Moreover, calculated course credit hours based on student workload data varied over time. Changes may have been affected by other activities impinging on available student study time, instructor-created changes in the course workload, or both. Without this data collection, however, the Curriculum Committee would have been unaware of course-related changes because most were not reported to the committee.
Question 2b: Did the Weekly Out-of-Class Time Data Show Evidence of Distributed Studying or of Intense Studying Before Tests?

For only two courses did the patterns of work per course show anything other than workload peaks before examinations. Those courses had significant homework expectations, and peaks were related to due dates. Distributed studying was not apparent, further suggesting that our goals of deeper learning were not being met as students were clearly moving from subject to subject on the basis of the next examination or project. ${ }^{6}$

\section{Question 2c: Were Week Quality Scores Correlated with Total Workload, In-Class Hours, or Out-of-Class Work Time?}

Week quality decreased as total work time increased. Students seemed to be most affected by the amount of work required outside of class and could tolerate relatively long hours in the classroom. Unfortunately maximizing in-class hours is not likely to provide opportunities for deep learning and would be more likely to steer students toward strategic or superficial learning. ${ }^{17}$ Zamor et al. saw disappointing results related to their curriculum revision in part related to more work than available hours and to more self-directed learning. ${ }^{5}$ Out-of-class hours tend to be more stressful than in-class hours when used as a trade-off, such as when instructors flip their classrooms or use assignments for knowledge application. Learning material or applying material is harder than reviewing or rereading material, even if it is better for retention. . $2,18^{2}$

Students reported that is hard to know when to stop studying. This is understandable with the current amount and complexity of the material in the curriculum. Hence, there is a strong likelihood of the 20-hour-per-week out-of-class work time continuing, because this seems to be the amount of time students can tolerate reviewing the material. To maintain any level of enjoyment in the learning process, in-class time and extra assignments would need to decrease. For the UMN CVM curriculum, the correlation data suggests that a cut-off of 35 hours per week of class time would keep the number of bad weeks to $25 \%$ or less. The curves can also be used to calculate likely week quality scores for known out-of-class time if other cut-offs are preferred.

\section{Question 2d: Was the Workload Achievable While Also Maintaining Student Well-Being?}

Students were spending close to the target of a 60-hour work week, but this target seems too high for well-being if it is consistently at that level. The maximum level of combined in-class and out-of-class time in our program seems to be approximately 54-56 hours with continuing improvements in week quality as that number decreases. At the 54- to 56-hour-per-week level, students feel like they can continue to work; this does not necessarily imply they have time for deep processing of information or are actually enjoying veterinary school. Additional challenges such as illness or outside stressors are difficult to accommodate at this level because of a lack of flexibility and free time. ${ }^{19}$ Because excessive academic stress is associated with lower 
grade point averages as well as decreased mental and physical health, pushing students beyond their capacity is not effective for a training program. ${ }^{20-22}$

With these results available, course credit hour calculations have been modified to include an exam-hour metric to more accurately reflect time spent on the course rather than adding exams and quizzes on top of the official workload. Conversations on credit hour calculations and restrictions continue. Faculty continue to identify alternative assessments and to focus content on core principles while reducing an emphasis on excessive detail. The survey results are also being considered as the UMN CVM looks toward further curriculum revision.

\section{Part 3: Curricular Flow and Integration}

\section{Question 3a:Did Students Identify and Appreciate Integration Efforts?}

Students clearly liked having the material integrated across courses, particularly if it was closely related in time. Occasionally students commented on the learning value of distributed reviews, but most only recognized the increased mental work involved with spaced learning. ${ }^{23}$ Students did identify missed opportunities. As an example, on the basis of comments related to learning physiology, we rescheduled microscopic anatomy to better align with physiology, making it a two-semester course in the process. Despite more positive survey comments on the integration in that first semester, integration scores actually decreased, potentially related to additional missed opportunities students identified across other courses. Current comments suggest creating more integrated blocks of content, particularly for the neurological and cardiovascular units because students are expected to understand blood flow in anatomy without having had the content and are trying to understand the components of the nervous system without having seen the anatomy.

Fourth-semester instructors in large animal courses made an obvious effort to pull related material from small animal courses, and the effort was noted by students and was likely the cause of improved integration scores in that semester. Time spent ensuring course coordinators and instructors had access to other course content has decreased as instructors have developed their new lectures and are less interested in revisions. Decreasing integration scores may also indicate a shift in content that has resulted in poorer alignment over time. For example, alignment of content across courses has required face-to-face meetings and deliberate planning. We have not been able to sustain those annually, and changes in content order, content emphasis, or instructor may have resulted in misalignment. More effort was actually expended between 2016 and 2017 to integrate content across courses in the third semester but with decreased integration scores. With more closely timed content, apparent or real contradictions between courses may be more obvious and more frustrating for students in that semester as they struggle to remember which answer is correct for which professor (and examination) and to identify the right answer. ${ }^{24}$ We are trialing team-taught sessions in that semester to remove some of the extra effort of integration and to enable real-time discussion of phrasing and meaning (e.g., incubation from disease transmission or incubation after disease diagnosis).

\section{Question 3b: Could Students Identify Excessive Redundancy and Curricular Gaps?}

Contrary to our hypothesis, students were unable to identify extraneous or advanced content compared with core content. When faced with an overload, they routinely asked for more frequent examinations but never for less content. We should have expected this from their viewpoint; we find that faculty similarly struggle to identify what is core for Day One practice versus what is more applicable to a specialty environment. ${ }^{25}$

\section{Question 3c: Were Week Quality Scores Correlated with the Perceived Level of Integration?}

As expected, week quality scores were positively associated with integration scores and negatively associated with examination hours. Students reported that integration opportunities provided positive reinforcement on their progress in learning the material as well as providing review and reinforcement of the material. The latter was particularly useful if it occurred before a test in a subject. Improved scores could also be related to a more positive outlook on the program in general. ${ }^{26}$

\section{Question 3d: Were Week Quality Scores Correlated with the Number of Examinations perWeek?}

To maintain at least $75 \%$ of week quality scores at 2 or higher, the break point for examinations appears to be 2-2.5 hours of exams or quizzes in a week. Testing has significant benefits for learning and retention, but excessive hours may lead to lack of sleep, superficial or strategic studying, cramming, and overall poorer retention instead of test-induced gains in learning. ${ }^{12,27,28} \mathrm{UMN} C V M$ students routinely have 4 hours of exams or quizzes per week. Most UMN CVM exams and quizzes are summative and count toward the student's final grade rather than toward mastery or pass-fail. The Curriculum Committee has set guidelines of roughly one test per course credit hour; most courses have slightly more than that. Quizzes have not been restricted because of their potential benefit in reviewing the material and ensuring that students are keeping up with the material; however, all exam hours will be considered as we review the curriculum.

\section{Part 4: Student Well-Being}

\section{Question 4a:Were Week Quality Scores Correlated with Sleep, Extracurricular Activities, Paid Employment, or Exercise?}

Week quality was positively correlated with getting at least 6 hours of sleep, non-curricular fun activities, and exercise. Most of our students participated in clubs and extracurricular activities, both veterinary and non-veterinary. As previously documented, such activities tend to improve well-being and create a more positive perspective in students. ${ }^{29,30} \mathrm{In}$ a similarly manner, sleep and exercise had strong positive benefits for UMN CVM students. Sleep has been shown to be protective for well-being and to improve resilience. ${ }^{4,8}$ Exercise can improve learning, mental and physical health, 
and mood; it may even be protective against stress-induced mental disorders. ${ }^{27,31,32}$ We have been sharing the exercise data with the classes in the hopes of stimulating new habits and encouraging those who do exercise to continue. Participating in these well-being activities is limited by the amount of time in the day.

We were surprised to find minimal correlation of week quality scores with paid employment. Paid employment hours could be simultaneously helpful for student learning by creating a framework for knowledge or skills connection $^{33,34}$ while at the same time having a negative effect on available study time. Required employment hours may also stimulate more effective study habits ${ }^{35}$ or have a threshold effect on week quality, with most of our students staying below that critical threshold. We continue to collect data for more analysis and verification of our findings.

Week quality decreased as the semester progressed and varied by semester. We found that students were not able to rebound as successfully as we had anticipated. In the early years of the curriculum revision, there were several bad weeks. Our assumption was that students would recover if these were followed by a lighter week. However, students did not regain energy and enthusiasm until after a true holiday. A lighter week generally meant low energy and less studying because of exhaustion and lack of a looming test. Scheduling more evenly spaced examinations and avoiding very light or very heavy weeks has been more successful in helping students persist mentally. The slog is not easy, but on the basis of workload survey comments and scores, it seems more doable. Improvements in workload may also be negated by the increased examination hours. ${ }^{4,29}$

Students also provided us with more and more scheduling preferences as time went on (Appendix 2). Not all could be accommodated at any given time, particularly with course related content restraints, but this permitted more purposeful planning and avoided challenging situations, such as excused absences for religious holidays conflicting with required classroom discussions in the active learning classroom, where lecture capture is not possible.

\section{Question 4b: Could Week Quality Scores Be Used as} an Early Warning System for Curricular Issues?

Moving the curricular survey data into the weekly workload survey increased response rates and usefulness of the data. Students were able to provide more relevant details closer to the actual event, and we were able to make some adjustments mid-semester, particularly in terms of conflicting content or missing background information.

We have used the workload survey in conjunction with curricular survey components to identify changes in out-of-class worktime, generally by seeing changes in student perceptions of the quality of each week compared with what was expected. As described earlier, we use chair time reports to know which weeks are likely to be stressful. When a week is unexpectedly bad, it is flagged, and we investigate the change. In a recent semester, we found an aberrant week was related to an open book quiz introduced by a new instructor. The quizzes in this course historically took 15-20 minutes and were low stress, designed to ensure that students were keeping up. This new quiz took 2 hours and was challenging. The change had not been included in the planning process, leading to a week with a much higher load than was originally identified. The stress level was communicated to all course coordinators. Several course coordinators made real-time changes, the college increased well-being activities, the students felt supported, and we were able to identify the cause and could better plan for the following year.

The workload survey has been a key component of our curricular evaluation. With the initial new curriculum, the survey identified work overloads in the fourth and fifth semesters along with low work levels in first semester. On the basis of the data, the Curriculum Committee made significant revisions to the initial plans, moving courses and content to give a more realistic first semester and more doable fourth and fifth semesters. These moves were challenging, particularly after a single iteration of the new curriculum. Courses moving forward in the curriculum had to be double taught or simultaneously taught to different cohorts. Integration across courses had to be reconstructed. All instructors had to alter their content relating to other courses and adjust to a differently prepared student (second-year vs. third-year student). Without the survey data demonstrating an acute need, it would have been very difficult to make the necessary changes, both for the Curriculum Committee and for the faculty.

We have also used comparison workload data to show the students that we are attempting to respond to their concerns and to recruit more students to participate in providing workload data. Showing the improvement in week quality from one year to the next on the basis of their input shows we are listening.

\section{LIMITATIONS}

The data are from one school with a culture of "just-in-case" knowledge dissemination (content heavy, trying to cover all possible career paths and eventualities) and a relatively high number of examination hours. It would be ideal to repeat the survey at other colleges with similar and dissimilar cultures. Assignments are also missing from our current picture and cause additional stress, particularly in the second-year program, not the least because of the multiple due dates that are required.

Our survey tool does need further work. Increased response rates with a better match of volunteers to the cohort population (men vs. women, etc.) would be invaluable. Although our response rates were not as high as we would like, the results were consistent over time and were validated by the full class during end-of-semester comment sessions and by student members of the Curriculum Committee. The response rate was also sufficient to convince faculty of its validity.

We would like to create an automated dashboard for the workload surveys with a means of flagging support personnel when week quality scores reach a certain threshold. The process is currently manual and may lag up to 2 weeks.

\section{SUMMARY}

Although the student perspective cannot answer all questions, it was invaluable as we implemented and revised our curriculum. Gaining a better understanding of what 
helped and what hindered student learning made it possible to adjust our schedules and courses to provide the best environment possible within our constraints and to enable us to plan better rather than solely react. Overall, week quality was most positively affected by student factors of sleep and exercise, and curricular factors of out-of-class work time, total course work time, and examination hours had the strongest negative effects. Integration efforts had a strong positive effect and were difficult to maintain. It was surprising to us that open time, in-class hours, and paid employment hours had minimal correlation with week quality. The weekly surveys provided a view of the curriculum that was not otherwise available and gave us a tool to identify which of our efforts was making the most difference in the students' view of the program. Unfortunately, it did not give much guidance on how to fix the problem. We do anticipate using the limit of 55 hours of course-related work and 2.5 hours of examinations per week with our curricular reviews, but we still struggle with removing content and making room for student well-being and deeper learning.

We continue to collect data at our institution to identify problem areas and successes. We identified one cohort with higher than average week quality scores compared with the other cohorts. Early data suggest they exercise more, participate in more weekday clubs, and have a stronger support network within the class; those factors and others are still being monitored to determine whether the trends continue. Other factors, such as innate resilience, mind-set, mental health awareness, and social connections may play roles in student well-being but are currently not assessed. $8,29,36$ Knowing which factors play the largest roles in student well-being would be highly beneficial and is an important next step.

\section{REFERENCES}

1 Root Kustritz MV, Molgaard LK, Malone E. Curriculum review and revision at the University of Minnesota College of Veterinary Medicine. J Vet Med Educ. 2017;44(3):459-70. https: / / doi.org/10.3138/jvme.0217029R. Medline: 28876985

2 Wilson K, Fowler J. Assessing the impact of learning environments on students' approaches to learning: comparing conventional and action learning designs. Assess Eval High Educ. 2010;30(1):37-41. https: / / doi. org /10.1080/0260293042003251770

3 Ilkiw JE, Nelson RW, Watson JL, et al. Curricular revision and reform: the process, what was important, and lessons learned. J Vet Med Educ. 2017;44(3):480-9. https://doi.org/10.3138/jvme.0316-068R. Medline: 28876993

4 Weston JF, Gardner D, Yeung P. Stressors and protective factors among veterinary students in New Zealand. J Vet Med Educ. 2017;44(1):22-8. https: / doi. org/10.3138/jvme.0116-014R1. Medline: 28206841

5 Zamor E, Chigerwe M, Boudreaux KA, et al. Approaches and study skills of veterinary medical students: effects of a curricular revision. J Vet Med Educ. 2017;44(3):490-501. https://doi.org/10.3138/jvme.1015176R1. Medline: 28876983
6 Sisti HM, Glass AL, Shors TJ. Neurogenesis and the spacing effect: learning over time enhances memory and the survival of new neurons. Learn Mem. 2007;14(5):368-75. https:// doi.org/10.1101/lm.488707. Medline: 17522028

7 Harden R, Stamper N. What is a spiral curriculum? Med Teach. 1999;21(2):141-3. https://doi. org/10.1080/01421599979752. Medline: 21275727

8 Cake MA, McArthur MM, Matthew SM, et al. Finding the balance: uncovering resilience in the veterinary literature. J Vet Med Educ. 2017;44(1):95-105. https:/ / doi. org/10.3138/jvme.0116-025R. Medline: 28206842

9 Cardwell JM, Lewis EG. Vocation, belongingness, and balance: a qualitative study of veterinary student well-being. J Vet Med Educ. 2017;44(1):29-37. https:/ / doi.org/10.3138/jvme.0316-055R. Medline: 28206847

10 Barre E, Esarey J. How much should we assign? Estimating out of class workload. Houston: Rice University Center for Teaching Excellence; 2016. Available from: http:/ / cte.rice.edu/blogarchive/2016/ 07/11/workload.

11 May SA, Silva-Fletcher A. Scaffolded active learning: nine pedagogical principles for building a modern veterinary curriculum. J Vet Med Educ. 2015;42(4):1-8. https://doi.org/10.3138/jvme.0415-063R. Medline: 26421513

12 Dunlosky J, Rawson KA, Marsh EJ, et al. Improving students' learning with effective learning techniques. Psychol Sci Public Interes. 2013;14(1):4-58. https:/ / doi. org/10.1177/1529100612453266. Medline: 26173288

13 Malone E. Evidence-based clinical skills teaching and learning: What do we really know? J Vet Med Educ. forthcoming.

14 Root Kustritz MV, Molgaard LK, Malone ED. Use of a model board exam and case study assessment for outcomes assessment of curricular change. Educ Heal Prof. 2018;1(1):11-8. https:/ / doi.org/10.4103/EHP.EHP_2_18.

15 Kember D. Interpreting student workload and the factors which shape students' perceptions of their workload. Stud High Educ. 2004;29(2):165-84. https:/ / doi.org/ 10.1080/0307507042000190778.

16 Rhind SM, Grant A. From studying the rain to studying the umbrella: mental health and well-being of veterinary medical students and graduates. J Vet Med Educ. 2017;44(1):1-2. https:/ / doi.org/10.3138/jvme.1116-170. Medline: 28206839

17 Chigerwe M, Ilkiw JE, Boudreaux KA. Influence of a veterinary curriculum on the approaches and study skills of veterinary medical students. J Vet Med Educ. 2011;38(4):384-94. https:/ /doi.org/10.3138/ jvme.38.4.384. Medline: 22130414

18 Silverthorn DU. Teaching and learning in the interactive classroom. Adv Physiol Educ. 2006;30(4):135-40. https: / / doi.org/10.1152/advan.00087.2006. Medline: 17108239

19 Killinger SL, Flanagan S, Castine E, et al. Stress and depression among veterinary medical students. J Vet Med Educ. 2017;44(1):3-8. https:/ / doi.org/10.3138/ jvme.0116-018R1. Medline: 28206849

20 Reisbig AMJ, Danielson JA, Wu T-F, et al. A study of depression and anxiety, general health, and academic 
performance in three cohorts of veterinary medical students across the first three semesters of veterinary school. J Vet Med Educ. 2012;39(4):341-58. https:/ / doi. org/10.3138/jvme.0712-065R. Medline: 23187027

21 Ruohoniemi M, Parpala A, Lindblom-Ylänne S, et al. Relationships between students' approaches to learning, perceptions of the teaching-learning environment, and study success: a case study of third-year veterinary students. J Vet Med Educ. 2010;37(3):282-8. https:/ / doi. org/10.3138/jvme.37.3.282. Medline: 20847338

22 Pickles KJ, Rhind SM, Miller R, et al. Potential barriers to veterinary student access to counselling and other support systems: perceptions of staff and students at a UK veterinary school. Vet Rec. 2012;170(5):124. https:/ / doi.org/10.1136/vr.100179. Medline: 22186377

23 Thomas AK, McDaniel MA. Metacomprehension for educationally relevant materials: dramatic effects of encoding-retrieval interactions. Psychon Bull Rev. 2007;14(2):212-8. https:/ /doi.org/10.3758/BF03194054. Medline: 17694903

24 Kay D, Kibble J. Learning theories 101: application to everyday teaching and scholarship. Adv Physiol Educ. 2016;40(1):17-25. https:/ /doi.org/10.1152/ advan.00132.2015. Medline: 26847253

25 D'Eon M, Crawford R. The elusive content of the medical-school curriculum: a method to the madness. Med Teach. 2005;27(8):699-703. https: / / doi. org/10.1080/01421590500237598. Medline: 16451890

26 Robins LS, Fantone JC, Oh MS, et al. The effect of pass/fail grading and weekly quizzes on first-year students' performances and satisfaction. Acad Med. 1995;70(4):327-9. https: / doi.org/10.1097/00001888199504000-00019. Medline: 7718068

27 Medina J. Brain rules: 12 principles for surviving and thriving at work, home, and school. 1st ed. Seattle: Pear Press; 2009.

28 Roediger III, HL. Relativity of remembering: why the laws of memory vanished. Annu Rev Psychol. 2008;59(1):225-54. https:/ / doi.org/10.1146/annurev. psych.57.102904.190139. Medline: 18154501

29 Bakker DJ, Lyons ST, Conlon PD. An exploration of the relationship between psychological capital and depression among first-year Doctor of Veterinary Medicine students. J Vet Med Educ. 2017;44(1):50-62. https:/ /doi. org/10.3138/jvme.0116-006R. Medline: 28206833

30 Jones ML, Rush BR, Elmore RG, et al. Level of and motivation for extracurricular activity are associated with academic performance in the veterinary curriculum. J Vet Med Educ. 2014;41(3):275-83. https:/ / doi. org/10.3138/jvme.1213-163R. Medline: 24981424

31 Ströhle A. Physical activity, exercise, depression and anxiety disorders. J Neural Transm. 2009;116(6):777-84. https:/ / doi.org/10.1007/s00702-008-0092-x. Medline: 18726137

32 Leary KA, DeRosier ME. Factors promoting positive adaptation and resilience during the transition to college. Psychology. 2012;3(12A):1215-22. https://doi. org/10.4236/psych.2012.312A180
33 Ruitenberg MFL, de Kleine E, van der Lubbe RHJ, et al. Context-dependent motor skill and the role of practice. Psychol Res. 2012;76(6):812-20. https:/ / doi. org/10.1007/s00426-011-0388-6. Medline: 22065045

34 Irby DM, Wilkerson LA. Educational innovations in academic medicine and environmental trends. J Gen Intern Med. 2003;18(5):370-6. https:/ / doi.org/10.1046/j.15251497.2003.21049.x. Medline: 12795736

35 Cox TD, Lemon MA. A curricular intervention for teaching and learning: measurement of gains of first-year student learning. J Scholarsh Teach Learn. 2016;16(3):1-10. https:/ / doi.org/10.14434/josotl. v16i3.19268

36 Whittington RE, Rhind S, Loads D, et al. Exploring the link between mindset and psychological well-being among veterinary students. J Vet Med Educ. 2017;44(1):134-40. https: / / doi.org/10.3138/jvme. 1215-192R. Medline: 28206831

\section{AUTHOR INFORMATION}

Erin D. Malone, DVM, PhD, DACVS, (D https://orcid.org/00000002-2527-2796) is Curriculum Coordinator, Department of Veterinary Population Medicine, University of Minnesota College of Veterinary Medicine, St Paul, MN 55 I08, USA. Email: malon00I@umn.edu.

Margaret V. Root Kustritz, DVM, PhD, DACT, is Assistant Dean for Academic and Student Affairs, Department of Veterinary Clinical Sciences, University of Minnesota College of Veterinary Medicine, St Paul, MN 55I08, USA.

Aaron Rendahl, PhD, is Statistician, Department of Veterinary Biological Sciences, University of Minnesota College of Veterinary Medicine, St Paul, MN 55I08, USA.

Laura K. Molgaard, DVM,Associate Dean for Academic and Student Affairs, Department of Veterinary Population Medicine, University of Minnesota College of Veterinary Medicine, St Paul, MN 55I08, USA.

\section{APPENDIX I: SEPTEMBER 20 I 8 TEMPLATE}

Thank you for participating in this workload survey.

Which week are you summarizing?

O week 1 -thru $9 / 7$

O week 2 -thru $9 / 14$

O week 3 - thru $9 / 21$

O week 4 - thru $9 / 28$

How would you rate your workload this week? Please count from last Saturday to today (Friday).

O Great week. I learned, slept, and had time for myself.

O Good but not great

O Average week. I can keep going like this but I did not have much free time.

O Not good but not horrible

O Bad week. I can't keep this up and I am not enjoying myself. 
Comments? Please give more info if this was a bad week.

How would you rate each of the following this week?

\begin{tabular}{|c|c|c|c|}
\hline & Great & Adequate & Poor \\
\hline $\begin{array}{l}\text { Progress toward } \\
\text { career goals } \\
\text { (learning what } \\
\text { you want or need } \\
\text { to learn) }\end{array}$ & $\bigcirc$ & $\bigcirc$ & $\bigcirc$ \\
\hline $\begin{array}{l}\text { Control over your } \\
\text { life (doctor appts, } \\
\text { family issues) }\end{array}$ & $\bigcirc$ & $\bigcirc$ & $\bigcirc$ \\
\hline $\begin{array}{l}\text { Control over } \\
\text { your studying } \\
\text { (planning, triage } \\
\text { mode, crisis } \\
\text { management) }\end{array}$ & $\bigcirc$ & $\bigcirc$ & $\bigcirc$ \\
\hline
\end{tabular}

Did you miss any classes this week (not in class or present in body only)? If so, why?
O NA
O Health appt for me
O Health appt for another (pet or human) Studying for a test
O Completing an assignment or online test Outside learning opportunity
Couldn't sit still any longer
O Other

Comments?

How many in class hours were scheduled for the following this week?

Oh $0.5 \mathrm{hr} 1 \mathrm{hr} 1.5 \mathrm{~h} 2 \mathrm{~h} 2.5 \mathrm{~h}$ 3h $3.5 \mathrm{~h} 4 \mathrm{~h} 5 \mathrm{~h} 6 \mathrm{~h}+$

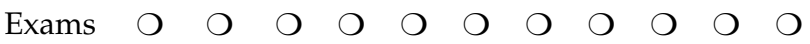

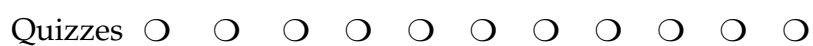

How many hours did you spend on each of these activities this week? Pick the closest amount. If $6 \mathrm{~h}+$, please include the amount below. (If it was in moodle, moodle can give you the info if needed

Oh $0.5 \mathrm{hr} 1 \mathrm{hr} 1.5 \mathrm{~h} 2 \mathrm{~h} 2.5 \mathrm{~h} 3 \mathrm{~h} 3.5 \mathrm{~h} 4 \mathrm{~h} 5 \mathrm{~h} 6 \mathrm{~h}+$

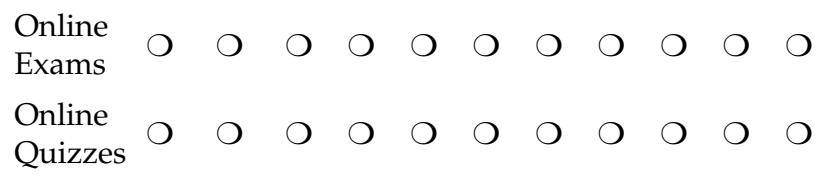

Hours if $6+$ and/or comments
How much out of class time time did you spend studying or working on these required courses this week? Exclude exam taking time recorded above.

0-1h 1-3hrs 3-5hrs 5-7hrs 7-10hrs 10-20hrs >20hrs

\begin{tabular}{|c|c|c|c|c|c|c|}
\hline Goal & O & ○ & ○ & $\bigcirc$ & ○ & $\bigcirc$ \\
\hline Prof Dev II & O & O & $\bigcirc$ & $\mathrm{O}$ & O & $\bigcirc$ \\
\hline Anat II & $\bigcirc$ & $\bigcirc$ & $\bigcirc$ & 0 & 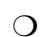 & $\bigcirc$ \\
\hline
\end{tabular}

How much out of class time time did you spend on each of these other items this week? If you aren't taking an elective, please choose NA. Exclude time recorded for exams above.

\begin{tabular}{|c|c|c|c|c|c|c|c|c|}
\hline & NA & $<1 \mathrm{~h}$ & $\begin{array}{l}1-3 \\
\text { hrs }\end{array}$ & $\begin{array}{l}3-5 \\
\text { hrs }\end{array}$ & $\begin{array}{l}5-7 \\
\text { hrs }\end{array}$ & $\begin{array}{c}7-10 \\
\text { hrs }\end{array}$ & $\begin{array}{c}10-20 \\
\text { hrs }\end{array}$ & $\begin{array}{l}>20 \\
\text { hrs }\end{array}$ \\
\hline Zoo topics & $\bigcirc$ & $\bigcirc$ & $\bigcirc$ & $\bigcirc$ & $\bigcirc$ & $\bigcirc$ & $\bigcirc$ & \\
\hline $\begin{array}{l}\text { Zoo and } \\
\text { wildlife } \\
\text { rounds }\end{array}$ & $\bigcirc$ & $\bigcirc$ & $\bigcirc$ & $\mathrm{O}$ & $\bigcirc$ & $\bigcirc$ & $\bigcirc$ & \\
\hline $\begin{array}{l}\text { Club } \\
\text { activities }\end{array}$ & $\bigcirc$ & $\bigcirc$ & $\bigcirc$ & $\bigcirc$ & $\bigcirc$ & $\bigcirc$ & $\bigcirc$ & \\
\hline Paying job & $\bigcirc$ & O & O & O & $\bigcirc$ & O & O & \\
\hline
\end{tabular}

Were you physically healthy this week?

Yes, felt fine

No illness, just tired

O Not healthy but not sick (eg injured)

O Mostly recovering

O Sick at least one day

Were you mentally healthy this week? Select all that apply.
$\square$ Yes, felt fine
$\square$ More fine than distressed
$\square$ More distressed than fine
$\square$ Anxious
$\square$ Depressed
$\square$ Other

Select all that apply. This week did you:

$\square \quad$ Feel rested

$\square$ Participate in weekday club, service or lunchtime activities

$\square$ Participate in weekend club or service activities Participate in non-veterinary fun activities

$\square$ Do something to improve your physical health Do something to improve your mental health

How much moderate intensity exercise did you do this week?
O none
O some but $<1$ hour $1-2$ hours
O 2-4 hours
O 4-6 hours
$0>6$ hours

How was the integration and coordination between courses this week?
O Excellent
O Good
Fair
P Poor 
Comments on the timing of material across courses and/or any contradictions across courses:

What background or knowledge did you need to have that was weak (if any)? Eg wish I had a better background in biochem

Suggestions for changes?:

\section{APPENDIX 2: STUDENT SCHEDULING PREFERENCES}

Students prefer

O No exams on Mondays

O Exams at 8:00 a.m.

O Exams spread out as much as possible, with at least 1 day between exams

O First exam in a course is the first exam in a week (if multiple exams)

O If a Monday exam, the previous exam should not have been on Friday
O Consistent scheduling so there are no large gaps in courses; however, integration of content is preferred over consistent scheduling

O Heavier days at the beginning of the week versus the end of the week

F Friday afternoons off

No full days of lecture

O Avoid Friday afternoon classes and Monday exams if there are weekend veterinary events

O Have a few courses finish early in the semester so not all classes are having finals and midterms at the same time

O Spread out laboratories as much as possible (to provide a break from lectures)

O Avoid active learning classroom sessions and exams on standard (even if not university) holidays

O Avoid one-time laboratories during national meetings (e.g., American Association of Equine Practitioners) 